\title{
Tres miradas sobre el Compromiso Social de la Educación Superior y el Aprendizaje Servicio
}

Mcllrath, Lorraine; Lyons, Ann; Munck, Ronaldo (Editors) (2012) Higher Education and Civic Engagement. Comparative perspectives. New York: Palgrave Macmillan.

Osman, Ruksana \& Petersen, Nadine (Editors) (2013) Service-learning in South Africa. Cape Town: Oxford University Press.

GUNI, Global University Network for Innovation (2014) Higher Education in the World Report 5: Knowledge, Engagement and Higher Education: Contributing to Social Change. New York: Palgrave MacMillan.

\section{Reseña}

\section{CLAYSS, Centro Latinoamericano de Aprendizaje y Servicio Solidario}

Hasta hace poco tiempo, parecía existir una brecha casi insalvable entre la bibliografía sobre responsabilidad social, compromiso universitario y aprendizaje servicio publicada en inglés y en castellano. Si bien los autores de lengua castellana suelen conocer y citar a algunos de los autores más clásicos de la literatura anglosajona (Furco, Jacoby, Eyler y muchos otros), una rápida revisión de las obras publicadas en inglés en los últimos años pone en evidencia un casi absoluto desconocimiento cuando no el desinterés- por parte de los especialistas del norte del planeta en cuanto a los desarrollos sobre este tema en Iberoamérica.

La escasez de traducciones de obras del castellano al inglés y la escasa presencia de académicos iberoamericanos en los foros de habla inglesa no sólo reduce la visibilidad de la centenaria tradición latinoamericana en estos temas, sino que también ha dificultado el diálogo "Sur-Sur" entre América Latina y los países de habla inglesa de África y el Sudeste asiático.

Sin embargo, en los últimos años, algunas obras en inglés han comenzado a cuestionar las miradas excesivamente anglosajonas y eurocéntricas sobre la responsabilidad social y el compromiso universitario. Por ello consideramos significativo presentar estas tres obras, que tienen en común ampliar la mirada hacia territorios usualmente inexplorados del compromiso universitario y el aprendizaje servicio. 
- Higher Education and Civic Engagement. Comparative perspectives es una obra colectiva, original ya desde sus autores: dirigida por dos irlandesas y un argentino radicado en Irlanda, y prologada por un sudafricano, incluye contribuciones de Medio Oriente, África y Australia, y también de España y América Latina. Desde su concepción inicial, apunta a establecer un auténtico "diálogo global" (p. XVIII), y a señalar los riesgos de que a nivel mundial se tome "un modelo nacional particular como la norma para el compromiso en la Educación Superior" (p. XVII). De hecho, las contribuciones desde Gran Bretaña y Estados Unidos son presentadas como contribuciones específicas, y no como un marco de referencia al que debieran ajustarse el resto de los contextos culturales.

La obra pone en diálogo no sólo diferentes miradas regionales, sino también diferentes conceptualizaciones y perspectivas sobre el compromiso en la Educación Superior, desde la visión de la Educación Superior como "fuerza para el cambio social" en el capítulo de Brenda Goruley, a los conceptos de "engaged scholarship" e investigación participativa (Ctuhill), "compromiso cívico" (Lyons) y "compromiso público" (Duncan y Manners).

Para los lectores de RIDAS no es el menor de los aspectos relevantes de esta obra que seis de sus trece capítulos se centren justamente en la reflexión, la práctica y la historia del aprendizaje servicio en diversos contextos nacionales y regionales.

- Service-learning in South Africa: este manual sudafricano está dirigido explícitamente a estudiantes universitarios involucrados en proyectos de aprendizaje servicio, y en función de esos destinatarios presenta un texto con glosarios y experiencias, sumamente "amigable". Sin embargo, por la profundidad de su marco teórico y la variedad de los casos de estudio presentados, consideramos que su lectura es sumamente recomendable también para especialistas y docentes.

Probablemente uno de los rasgos más originales de la obra, y el que más la aproxima a las miradas latinoamericanas sobre el aprendizaje servicio solidario, es que desde la introducción Osman y Petersen plantean con mucha claridad las diferencias epistemológicas y políticas entre un aprendizaje servicio basado en el paradigma de la filantropía o en el de la transformación y la justicia social.

Desde una fuerte opción por este segundo paradigma, la obra diferencia las prácticas desarrolladas desde la visión "hegemónica" de las fundadas en la valoración de la "otredad" y la reciprocidad, y subrayan la importancia de los aportes de la pedagogía crítica al aprendizaje-servicio. También distingue entre proyectos "basados en la comunidad" y "basados en el contenido curricular", 


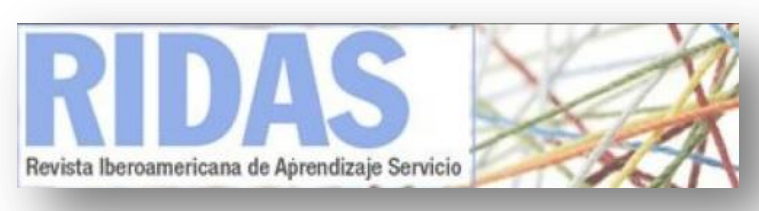

señalando los riesgos de este último de confundir a la comunidad como un simple espacio de práctica de los conocimientos adquiridos en el aula, ignorando la riqueza de los conocimientos presentes en la comunidad. Desde esta perspectiva, se dedica un capítulo central al proceso de integrar la voz de la comunidad en los proyectos de aprendizaje-servicio (Du Plessis-Van Dyk). La obra incluye también seis estudios de casos de programas de aprendizaje servicio desarrollados por universidades sudafricanas.

Los lectores latinoamericanos encontrarán familiar que la obra encara frontalmente la vinculación entre educación y política, un vínculo escasamente explorado en la literatura de lengua inglesa sobre aprendizaje servicio.

- Knowledge, Engagement and Higher Education: Contributing to Social Change es el quinto de los informes publicados por GUNI (Global University Network for Innovation). Este Observatorio mundial auspiciado por UNESCO -con sede en la Universidad Politécnica de Cataluña al momento de la edición- convocó a más de 70 especialistas de todo el mundo para componer un "estado de la cuestión" que aborda el tema del compromiso de la Educación Superior con el cambio social. Los directores de la obra son Budd Hall, un especialista en "community based research", y Rajesh Tandon, líder de la organización india PRIA (Society for Participatory Research in Asia), quienes son también los responsables de la Cátedra UNESCO de "Community Based Research and Social Responsibility in Higher Education".

La obra se estructura en seis secciones. La primera presenta el contexto y los desafíos globales para la Educación Superior. La segunda parte enfoca en la cuestión del conocimiento en relación al compromiso universitario. En esta sección se discute el concepto de "democracia del conocimiento" y dos contribuciones latinoamericanas abordan los conceptos de "responsabilidad social" (Vallaeys) y "compromiso social" universitario (De la Fuente y Didriksson). Una breve tercera sección se centra en las tendencias y progresos en la investigación sobre conocimientos y compromiso en la Educación Superior (Granados Sánchez y G. Puig). La cuarta sección incluye siete capítulos dedicados a las diferentes regiones del mundo, incluyendo estados de la cuestión, buenas prácticas y contribuciones particulares. Cabría destacar que el capítulo 5 de esta sección, dedicada a Europa (a cargo de Benneworth y Osborne), se centra en gran medida en la situación de Gran Bretaña y Escandinavia y omite llamativamente toda referencia al Aprendizaje servicio y a la experiencia española de voluntariado universitario y redes de ApS. El capítulo 7, dedicado a América Latina y el Caribe (a cargo de Nieves Tapia) intenta 
dentro de las constricciones del formato de la obra presentar la variedad de experiencias de la región, e intenta establecer algunas correlaciones entre los conceptos en inglés adoptados por la obra y los empleados en el castellano latinoamericano en la Educación Superior (pp. 274-275). En la quinta sección se ofrece una visión hacia el futuro y posibles pistas para la acción, y la sexta y última sección ofrece una selección bibliográfica.

Si bien la obra no ofrece más que una atención relativamente marginal al Aprendizaje servicio, entendemos que puede resultar de gran utilidad, especialmente por los debates epistemológicos que plantea.

En definitiva, estas tres obras son de consulta sumamente recomendable no sólo para la Educación Superior, sino -por la amplitud de sus reflexiones y perspectivastambién para docentes y practicantes del aprendizaje servicio en los centros educativos y las organizaciones sociales que trabajan con niños y adolescentes. 